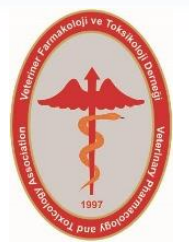

Veteriner Farmakoloji ve Toksikoloji Derneği Bülteni

Bulletin of Veterinary Pharmacology and Toxicology Association

e-ISSN 2667-8381, 12 (1): 15-20, 2021

DOI: $10.38137 /$ vftd.900797

\title{
TAMAMLAYICI-GELENEKSEL TIP KAPSAMINDA FITOTERAPİ VE KANSER YAKLAŞIMI
}

\author{
İsmail KURHAN ${ }^{1 \mathrm{a}}$, Hüsamettin EKİCİ ${ }^{\text {b }}$ \\ ${ }^{1}$ Kırıkkale Üniversitesi Veteriner Fakültesi, Farmakoloji ve Toksikoloji Anabilim Dalı, Kırıkkale
}

ORCID $^{\mathrm{a}}$ : 0000-0001-9895-9241, ORCID $^{\mathrm{b}}$ : 0000-0001-6403-737X

\author{
*Sorumlu Yazar: İsmail KURHAN \\ Geliș Tarihi: 21.03.2021 \\ E-Posta: i.kurhan@hotmail.com \\ Kabul Tarihi: 13.04.2021
}

\begin{abstract}
ÖZET
Fitoterapi özellikle kanser hastaları tarafindan sıklıkla başvurulan tedavi yöntemlerindendir. $\mathrm{Bu}$ incelemede fitoterapinin kanser ile ilişkisi ve kanser türlerinde farmakolojik ilaç kullanımına ek olarak tercih edilmesi değerlendirilmiştir. Literatür 2000- 2021 yılları arasında yayınlanmış fitoterapi çalışmaları yönünden taranmıştır. Veriler "Pubmed ve Siencedirect" gibi veri tabanlarında "complementary and alternative medicines, phytotherapy, herbal medicine, cancer" kelimeleri aranarak elde edilmiştir. Fitoterapinin Çin ve Güney Kore gibi uzak doğu ülkelerinde yaygın bir şekilde kullanıldığı, ilk uygulandığ Mezopotamya bölgesi sınırları içerisindeki Filistin'de ise kullanımının \%90 düzeylerinde olduğu gözlenmiștir. Gelișmiș ülkelerde, Uzakdoğu ülkelerine kıyasla daha az tercih edilen bitkisel ilaç uygulamalarının günümüzde daha çok tercih edildiği görülmüştür. Bunun nedenleri arasında geleneksel tıbbi yöntemler ve farmakolojik ilaç kullanımlarının yan etkileri sayılmaktadır. Ayrıca kanser vakalarındaki yaygınlık oranlarının yükselmesi bu yönelimi desteklemektedir. 2020 yılı dünya kanser vakaları; cinsiyet gözetmeksizin göğüs, akciğer, kolo-rektal, ölümler; akciğer, kolo-rektal, karaciğer şeklinde sıralanmaktadır. Fitoterapi tahmin edilemeyen yan etkilerine rağmen tüm dünyada hızla uygulanmaya devam etmektedir. Özellikle modern tıbbın tam olarak tedavi edemediği kanser gibi hastalıkların olması bunu tetiklemektedir. Sonuçta, kontrolsüz bitkisel ilaç kullanımı geleneksel tedavilerde tehditler ortaya çıkartmakta, bu durum ülkeleri yasal düzenlemeler yapmaya teşvik etmektedir. Yapılması gereken, fitoterapi uygulamalarında kullanılan bitkilerin farmakolojik ve toksikolojik parametrelerinin belirlenmesi, belirlenen parametreler ile bitkisel ilaçların kalite, güvenlik ve etkinlik yönünden standartlarının oluşturulmasıdır.
\end{abstract}

Anahtar Kelimeler: Bitkisel İlaç, Fitoterapi, Kanser, Tamamlayıcı ve Alternatif Tıp.

\section{PHYTOTHERAPY AND CANCER APPROACH IN COMPLEMENTARY- TRADITIONAL MEDICINE}

\begin{abstract}
Phytotherapy is one of the most frequently used treatment methods, especially by cancer patients. In this review, the relation of phytotherapy with cancer and its preference in addition to the use of pharmacological drugs in cancer types were evaluated. The literature was reviewed in terms of phytotherapy studies published between 2000-2021. The data were obtained by searching the words "complementar-alternative medicines, phytotherapy, herbal medicine, cancer" in databases such as "Pubmed and Siencedirect". It has been observed that phytotherapy is widely used in Far East countries such as China and South Korea, and its use is around $90 \%$ in Palestine within the borders of Mesopotamia where it was first applied. The reasons for this are the side effects of traditional medical methods and pharmacological drug use. Besides, the increase in the prevalence rates in cancer cases supports this trend. World cancer cases in 2020 are listed as breast, lung, colo-rectal, and deaths as lung, colo-rectal, liver regardless of gender. Phytotherapy continues to be applied rapidly all over the world despite its unpredictable side effects. Especially the presence of diseases such as cancer that modern medicine cannot fully cure triggers this. As a result, uncontrolled use of herbal medicine creates threats in traditional treatments, and this situation encourages countries to make legal regulations. Thing to do is to determine the pharmacological and toxicological parameters of the plants used in phytotherapy applications, it is to establish the standards of herbal medicines in terms of quality, safety and efficacy with the determined parameters.
\end{abstract}

Keywords: Cancer, Complementary and Alternative Medicines, Herbal Medicine, Phytotherapy. 


\section{GİRIŞ}

Geleneksel tıp (TM) sağlık halinin sürdürülebilmesi amacıyla hastalıkların önlenmesi, teşhisi ve tedavisi için kullanılan çoklu kültürel inanç ve deneyimle harmanlanmış bilgi, birikim ve uygulamalar yığını olarak tanımlanabilir (WHO, 2013). Çoklu kültürel aktarımlar “Geleneksel Çin Tıbbı, Geleneksel Hint Tibb1, Greko-Romen Tibbı, Osmanlı Tibbı" gibi ülke sinırları ya da kültürleri ile sinırlandırılmaktadır. Tamamlayıcı ve alternatif tıp (CAM) terimleri ise bir ülkenin kendi TM anlayışının ötesinde daha geniş sağlık uygulamalarını kapsamaktadır. CAM/TM terimlerinin tanınması ve düzenlenmesi ülkelere göre önemli ölçüde farklılık gösterirken bazı ülkelerde CAM ve TM benzer anlamlarda da kullanılmaktadır (Mordeniz, 2019). Eski zamanlarda şifalı bitkilerden ilaçların elde edilmesi, günümüzde insanlığı hastalıktan doğrudan veya dolaylı olarak kurtaran mevcut mucizevi bileşiklerin keşfine yol açmıştır (Kurhekar, 2021). Bitkilerle tedavi, modern tıbbi yöntemlerin dışında yer alan fakat modern tıbbi yöntemlere en yakın tedavi uygulamalarıdır (Heinrich, 2017). Fitoterapi; tıbbi bitkilerin, geleneksel kullanımı, deneysel gözlemler, in vitro, in vivo ve terapötik etkilerin klinik incelemesinin sistematik bir değerlendirmesine dayanan uygulanmasıdır. Tamamlayıcı olarak adlandırılan tüm terapiler arasında fitoterapi en fazla bilimsel desteği alan terapidir (Ghosh, 2016). İnsanlık tarihinde çok kadim geçmişe sahip bu yöntem ilk kez 19. yy başlarında yaşamış Fransız hekim Henri Leclerc tarafından literatüre kazandırılmıştır. Leclerc'in fitoterapiyi, bitkileri kullanarak hastaları tedavi etme anlamında La Presce Medical adlı dergide kullandığı bilinmektedir (Yurdakök, 2010; Kurhekar, 2021). Bitkisel ilaçlar, aktif bileşen yapıda bitkilerin kısımlarını veya diğer bitki materyallerini veya kombinasyonlarını içeren şifalı bitkiler, bitkisel materyaller, bitkisel preparatlar ve bitmiş bitkisel ürünleri kapsar. Bu geniş bağlamda fitoterapi, dünya üzerindeki pek çok toplum tarafindan hastalıklardan korunma ve tedavi amaciyla öncelikli olarak tercih edilmektedir. Zamanla teknoloji gelişmiş ve bitkisel tedavi yerini modern ve sentetik ilaçlara bırakmıştır (Conway, 2011; WHO, 2013).

Çağımızda, daha önce tanımlayamadığımız ve bu günkü modern tıbbi yöntemlerle tedavi edemediğimiz kanser gibi hastalıkların mevcudiyeti fitoterapiyi yeniden popüler konuma taşımıştır. Özellikle kanserin morbiditesi ve mortalitesindeki engellenemez artış hastaların hayata tutunma arayışlarını çeşitlendirerek, onları öncelikli olarak bitkisel tedaviye sürüklemektedir (Wang ve ark., 2020). Kanser tedavisinde kullanılan modern yöntemler ve farmakolojik ilaçların pahalı olması, hasta konforunu düşüren ciddi yan etkiler ve toplum baskısı gibi nedenler bu yönelimin başında gelmektedir. Fitoterapi uygulamalarında bitkiler saflaştırılmadan ihtiva ettiği her türden bileşenle komplike kullanıldığı için daha etkili olduğu ve yan etkiden ari olduğu düşünülmektedir. Bazen bitkilerdeki bileşenlerin sinerjik etkisi veya toksiteyi nörtalize etme durumu hastaları rahatlatmaktadır. Ancak tersi durumlarla da karşılaşılmakta ve rutin tedavi olumsuz etkilenmektedir (Pezzani ve ark., 2019). Birçok ülkenin sağlık sistemine entegre olmayan geleneksel ve tıbbi tedavi uygulamalarının entegrasyonu amaciyla WHO üye devletler nezdinde stratejiler geliştirmektedir. Strateji, üye devletleri proaktif politikalar geliştirmede ve geleneksel tıbbın popülasyonlarını sağlıklı tutmada oynadığ rolü güçlendirecek eylem planlarını uygulamaları için desteklemeyi amaçlamaktadır (WHO, 2013). Bu amaçla üye devletler yeni düzenlemelerle 
önlemlerini genişletmektedir (Şekil 1).

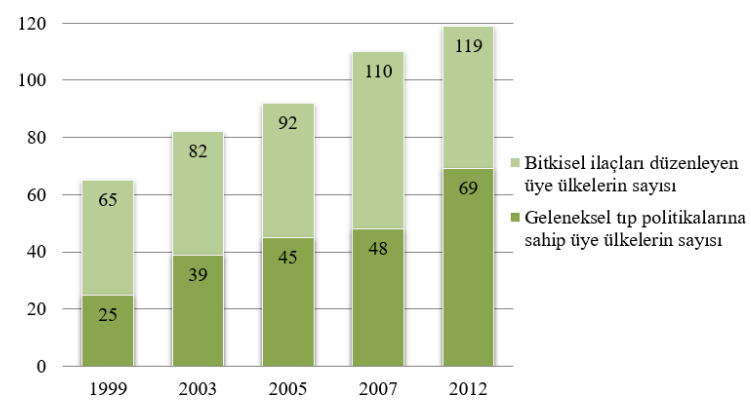

Şekil 1. WHO Geleneksel Tip Stratejisinde tanımlanan ülke ilerleme göstergeleri (WHO, 2013).

\section{Fitoterapi ve Kanser}

Fitoterapinin Çin ve Güney Kore gibi uzak doğu ülkelerinde yaygın bir şekilde kullanıldığı, ilk uygulandığı Mezopotamya bölgesi sinırları içerisindeki Filistin'de ise kullanımının $\% 90$ düzeylerinde olduğu gözlenmiş̧ir. Bitkisel ilaç uygulamaları gelişmiş ülkelerde, Uzakdoğu ülkelerine kıyasla daha az tercih edilirken günümüzde tamamlayıcı ve alternatif tıp olarak yüksek bir popülariteye sahiptir. Amerika Birleşik Devletleri, Almanya, İsviçre, Küba, Japonya, Şili gibi ülkelerde nüfusun \%40'ından fazlası geleneksel ve tamamlayıc1 tıbbı genellikle yılda bir kez kullanmaktadır (Park ve ark., 2016). Almanya, gelişmiş ülkeler arasında fitoterapinin tanıtımı ve kullanımında önde gelen ülkedir ve reçetelerinin yaklaşı \%40'ını bitkisel tıbbi ürünler oluşturmaktadır (Santos ve ark., 2011). Bunun nedenleri arasında geleneksel tıbbi yöntemler ve farmakolojik ilaç kullanımlarının yan etkileri sayılmaktadır. Nitekim kanser hastalarının kemoterapiye bağlı kabızlık ile baş etmek için kullandıkları TM/CAM ilaçların araştırıldığı bir çalışmada katılımcılar arasında hastaların kullandığı en yaygın yöntemin \%97,1 ile fitoterapi olduğu tespit edilmiştir (Toygar ve ark., 2020). En az gelişmiş ülkeler incelendiğinde düşük maliyeti ve kolay erişimi nedeniyle fitoterapi birinci basamak sağlık hizmeti olmaya devam etmektedir (Leite ve ark., 2021). Ayrıca kanser vakalarındaki yaygınlık oranlarının yükselmesi bu yönelimi desteklemektedir. 2020 yılında dünya çapında tahminen 19,3 milyon yeni kanser vakası ve 10 milyon kanser kaynaklı ölümün meydana geldiği ifade edilmektedir (Sung ve ark., 2021). Her iki cinsiyet birlikte, tüm vakaların yarısının ve kanser ölümlerinin $\quad \% 58,3^{\prime}$ ünün $\quad 2020$ 'de Asya'da gerçekleştiği tahmin edilmektedir. Avrupa, dünya nüfusun $\% 9,7$ 'sini temsil etmesine rağmen, toplam kanser vakalarının \%22,8'ini ve kanser ölümlerinin \%19,6'sını oluşturmaktadır. Bunu Amerika'nın $\% 20,9$ 'u ve dünya çapında ölümlerin \%14,2'si izlemektedir. Diğer bölgelerin aksine, Asya'da $(\% 58,3)$ ve Afrika'da $(\% 7,2)$ kanser türlerinin farklı dağılımları ve daha yüksek vaka nedeniyle kanser ölümlerinin payı, insidans payından (sırasıyla \%49,3 ve \%5,7) daha yüksek olduğu görülmektedir. Kadın meme kanseri en sık teşhis edilen kanserdir (toplam vakaların \%11,7'si). Bunu akciğer $(\% 11,4)$, kolorektal $(\% 10)$, prostat $(\% 7,3)$ ve mide $(\% 5,6)$ kanserleri takip etmektedir. Akciğer kanseri, cinsiyet fark etmeksizin kanserden ölümlerin (toplam kanser ölümlerinin \%18’i) başlıca nedenidir. Bunu kolorektal $(\% 9,4)$, karaciğer $(\% 8,3)$, mide $(\% 7,7)$ ve kadın meme $(\% 6,9)$ kanserleri izlemektedir. Akciğer kanseri, erkeklerde en sık meydana gelen kanserdir ve kanserden ölümlerin önde gelen nedenidir. Bunu insidans için prostat ve kolo-rektal kanser ve ölüm için karaciğer ve kolo- rektal kanser izlemektedir. Kadınlarda meme kanseri en sık teşhis edilen kanserdir ve kanserden ölümlerin önde gelen nedenidir (IARC, 2021). Kanser yükü tüm İnsani Gelişme Endeksi (IGGE) düzeylerinde önemli ölçüde artmakta ya da yön değiştirmektedir. En gelişmiş ülkelerde yaygın olan (meme, akciğer, kolorektum, 
prostat) kanser türlerinin yoksullukla ilişkili kanserlerle (rahim ağzı, karaciğer, mide) yer değiştirdiği gözlenmiştir (Fidler ve ark., 2016). Yapılan projeksiyonlarda 2020'deki 19,3 milyon vakadan \%47'lik bir artışla 2040 yılında 28,4 milyon vakaya çıkması tahmin edilmektedir. Artışın göreli büyüklüğü, en çok İGE’nin düşük olduğu ülkelerde (\%95) ve orta İGE ülkelerinde (\%64) olarak hesaplanmıştır (Sung ve ark., 2021b). Kanserin gelecekte insanlık için daha büyük riskler ve tehditler içerecek olması, bitkisel tedavi çalışmalarından alınan olumlu sonuçlarla değerlendirilince fitoterapiye yönelim artışı hızlanmaktadır (Jones ve ark., 2019).

Bazı araştırmalar kanser immunoterapisi açısından bitkisel tedavinin olumlu yanıtlarını ortaya koymuştur. Akciğer, meme ve yumurtalık kanseri hücreleri gibi tümör hücrelerinin proliferasyonunu ve metastazını inhibe ederken apoptozunu teşvik ettiğini göstermiştir. Prostat kanserinin anjiyogenezini ve tümör büyümesini baskıladığı gösteren çalışmalar da bildirilmiştir (Wang ve ark., 2020). Başka bir çalışmada ise çoklu bitkisel karışımdan oluşan bir fitoterapi ürününün makrofajların tümör hücreleri üzerindeki öldürücü etkilerini güçlendirdiği verisine ulaşılmıştır (Liang ve ark., 2018). Son yıllarda, tümörle ilişsili makrofajlarda, fagositozunu ve antitümör immün fonksiyonlarını inhibe eden programlanmış hücre ölüm proteini (PD-1)'i eksprese edebildiğinin bulunması (Villadolid ve Amin, 2015; Gordon ve ark., 2017) bunu teyit etmiştir. Kemoterapi ile kombine astragalus bitkisi tedavisinin, bu kimyasal ilaçların neden olduğu toksisiteyi azalttığı bildirilmiştir (Auyeung ve ark., 2016; Auyeung ve ark., 2016). Geleneksel Çin tıbbında sindirim sistemi rahatsızlıklarında uzun süreler kullanılan Baizhu ve Cangzhu'nun yapısındaki atractylenolides maddesinden dolayı çoklu tümör endikasyonlarına karşı belirgin antikanser etkiler sergilediği tespit edilmiştir (Bailly, 2021).

Bitkisel ürünleri içeren tedaviler potansiyel faydalar göstermesine rağmen her durumda tamamen doğal ve güvenli değildir (Jones ve ark., 2019). Bitkisel ürünler doğal kaynaklardan gelse de, içlerinde bulunan biyoaktif bileşenler, ilaç metabolize eden enzimlerin veya taşıyıcıların indüksiyonu veya inhibisyonu yoluyla istenmeyen etkileşimlere yol açabilirler (Nanjappan ve ark., 2018). Bu, bitkisel ürünlerin çoğunun hiç test edilmemiş olması ve kullanımlarının genellikle yeterli bir şekilde izlenmemesinin sonucudur. (National Cancer Institute, 2015). Bitkisel ilaçların kullanımı giderek arttığı için toksikolojik etki mekanizmalarının aydınlatılması gerekmektedir. Bu ürünlerin tüketicilerinin yanlış dozaj ve uygulamalarıyla ilişkili olabilecek risklerin farkında olması için yeterli bilgiye ihtiyaç vardır (Oyedepo ve Palai, 2021). Özet olarak denemede fitoterapi ve kanser ilişkisinin incelenmesi amaçlanmıştır.

\section{SONUÇ}

Sonuç olarak, dünyanın içerisinde bulunduğu ekonomik sıkıntılar, iklim değiş̧ikliği, nüfus artışı ve yaşlanma gibi faktörler hesap edildiğinde TM/CAM'a olan taleplerin artacağı tahmin edilmektedir. Dolayısıyla fitoterapinin geçmişe göre çok daha fazla tercih edilen bir yöntem olarak karşımıza çıkacağı düşünülmektedir. Ancak bitkilerin tedavide saflaştırma ve eksrakte etme gibi yöntemler kullanılmadan uygulanması önemli bir toksik yan etkiyi oluşturabilmektedir. Bitkiler, yapılarında alkaloid, polisakkarit, glikozitler ve flavonoidler gibi bilinen ya da hala tespit edilememiş birçok maddeyi barındırırlar. Bu maddeler bilinen ve bilinmeyen pek çok biyolojik ajan ve reseptörle 
etkileşime girerler ve istenmeyen klinik vakalar meydana getirebilirler. Kanser tedavi protokollerinde kullanılan kemoterapi ve radyoterapi gibi ilaç ve yöntemlerin yanında, fitoterapi uygulamalarının artan ivmeyle kullanıldığı kabul edilmektedir. Özellikle modern tıbbi tedavi yöntemlerinin tamamlandığı ve sonuç alınamayan vakalarda; ayrıca ilaç yan etkilerinin azaltılması amaciyla sıklıkla tercih edilmektedir. $\mathrm{Bu}$ yönelimlerden bazen olumlu sonuçlar alınabilmektedir. Ancak birçok vakada istenmeyen sonuçlarla karşılaşıldığı rapor edilmiştir. Yapılması gereken, fitoterapi uygulamalarında kullanılan binlerce yıllık birikimin nicel klinik çalışmalarla ortaya konulması, devamında bitkilerin farmakolojik ve toksikolojik parametrelerinin belirlenmesi, sonuçların kalite, güvenlik ve etkinlik yönünden standardizasyonlarının yapılarak kullanılmalarıdır. Böylece fitoterapiye bağlı kanser tedavisinde daha iyi sonuçların alınabileceği düşünülmektedir.

\section{KAYNAKLAR}

Auyeung, K. K., Han, Q. Bin and Ko, J. K. (2016). Astragalus membranaceus: A review of its protection against inflammation and gastrointestinal cancers. American journal of Chinese medicine, 44(1), 1-22.

Bailly, C. (2021). Atractylenolides, essential components of Atractylodes-based traditional herbal medicines: Antioxidant, antiinflammatory and anticancer properties. European journal of pharmacology, 891, 173735

Begüm, Y. (2010). Türkiye'de Yetişen Eryngium Kotschyı (Boğa Dikeni) ve Eryngıum Marıtımum (Deniz Boğadikeni) Bitkilerinin Sitotoksik Etkilerinin HEP2, HEPG2, VERO ve U138 MG Hücre Kültürlerinde Araştırılması. Ankara, Türkiye.

Conway, P. (2011). The therapeutic relationship in phytotherapy. Elsevier

Fidler, M. M., Soerjomataram, I., Bray, F. (2016). A global view on cancer incidence and national levels of the human development index. International journal of cancer, 139(11), 24362446.

Ghosh, D. Seed to patient in clinically proven natural medicines in nutraceuticals. Efficacy, Safety And Toxicity. Elsevier Inc.; 2016. pp. 925-931.

Heinrich Michael (2017). Phytotherapy | medicine |
Britannica. Erişim adresi: [https://www.britannica.com/science/phytothera py]. Erişim tarihi: 17.02.2021.

IARC (2021). Cancer Today. International Agency for Research on Cancer. Erişim adresi: [https://gco.iarc.fr/today/home]. Erişim tarihi: 17.02.2021

Jones, E., Nissen, L., McCarthy, A., Steadman, K., Windsor, C. (2019) Exploring the use of complementary and alternative medicine in cancer patients. Integrative cancer therapies, 18 , p. 153473541984698

Kurhekar, J. V. İn preparation of phytopharmaceuticals for the management of disorders. Ancient and Modern Practices in Phytomedicine. Elsevier; 2021. pp. 55-75.

Leite, P. M., Camargos, L. M., Castilho, R. O. (2021). Recent progess in phytotherapy: A Brazilian perspective. European journal of integrative medicine, 41, p. 101270.

Liang, P., Guo, J., Li, S., Guan, Q., Vanderheyden, T., So, A., Wang, Y., Chen, T., Du, C. (2018). Prevention of prostate tumor development by stimulation of antitumor 1mmunity using a standardized herbal extract (Deep Immune ${ }^{\circledR}$ ) in TRAMP Mice. Evidence-based complementary and alternative medicine, 2018, 1-12.

Mordeniz, C. (2019). Introductory Chapter: Traditional and Complementary Medicine.IntechOpen

Nanjappan, S., Paul, D., Bolla, L. Assessing herb-drug interactions of herbal products with therapeutic agents for metabolic diseases: analytical and regulatory perspectives. Studies in Natural Products Chemistry. Elsevier B.V.; 2018. pp. 283-322.

National Cancer Institute (2015). Complementary and Alternative Medicine (CAM). Erişim adresi: [https://www.cancer.gov/about-

cancer/treatment/cam]. Erişim tarihi: 19.02.2021.

Oyedepo, T. A., Palai, S. Herbal remedies, toxicity, and regulations. Preparation of Phytopharmaceuticals for the Management of Disorders. Elsevier; 2021. pp. 89-127.

Park, Y. L., Huang, C. W., Sasaki, Y., Ko, Y., Park, S., Ko, S. G. (2016). Comparative study on the education system of traditional medicine in China, Japan, Korea, and Taiwan. Explore: The journal of science and healing, 12(5), pp. 375383.

Pezzani, R., Salehi, B., Vitalini, S., Iriti, M., Zuñiga, F. A., Sharifi-Rad, J., Martins, N. (2019). Synergistic effects of plant derivatives and conventional chemotherapeutic agents: An update on the cancer perspective, Medicina (Lithuania), 55(4), 110

Santos, R. L., Guimaraes, G. P., Nobre, M. S. C., Portela, A. S. (2011). Analysis about phytotherapy as an integrating practice in the Brazilian Unified Health System (Uhs). Revista brasileira de plantas medicinais, 13(4), 486-491.

Sung, H., Ferlay, J., Siegel, R. L., Laversanne, M., Soerjomataram, I., Jemal, A. Bray, F. (2021). 
Global cancer statistics 2020: GLOBOCAN estimates of incidence and mortality worldwide for 36 cancers in 185 countries. CA: A cancer journal for clinicians.

Toygar, I., Yeşilbalkan, Ö. U., Kürkütlü, M., Aslan, A. (2020). Complementary and alternative medicines used by cancer patients to cope with chemotherapy-induced constipation. Complementary therapies in clinical practice, 39, 10108.

Villadolid, J., Amin, A. (2015). Immune checkpoint inhibitors in clinical practice: Update on management of immune-related toxicities. Translational lung cancer research, 4(5), 560.

Wang, Y., Zhang, Q., Chen, Y., Liang, C. L., Liu, H., Qiu, F., Dai, Z. (2020). Antitumor effects of immunity-enhancing traditional Chinese medicine. Biomedicine and pharmacotherapy, $121,109570$.

WHO., (2013). World Health Organization. Traditional Medicine Strategy 2014-2023, World Health Organization. Elsevier. pp. 1-76. 